\title{
Sylvia Plath - en av de unge døde
}

Ved M arianne Egeland

Den amerikanske dikteren Sylvia Plath var ganske ukjent da hun i februar 1963 tok livet av seg, 30 år gammel, etter en intens skriveraptus. Bare blant noen få innvidde var hun ansett for å være en poetisk begavelse. Selvmordet endret dramatisk på dette, noe kollegaen A nne Sexton umiddelbart visste ville bli resultatet. Sylvia Plath ble kanonisert som geni og dyrket så å si verden over.

A nne Sexton forteller i en kort minneartikkel om Sylvia Plath hvordan de i Boston våren 1959 pleide å gå ut sammen og da diskuterte "butikk" på flere måter. De var begge depressive, hadde vært igjennom sammen brudd, selvmordsforsøk og innleggelse og brukte erfaringene i skrivingen sin. Deres bruk av ordet selvmord var spesiell:

0 fte, veldig ofte snakket Sylvia og jeg utførlig om våre første selvmord; utførlig, i detalj og i dybden innimellom gratis potetgull. (...) Vi snakket om døden med oppbrent intensitet, begge tiltrukket av den som møll til en lyspære. Vi sugde på den! $\mathrm{H}$ un fortalte historien om sitt første selvmord i omtenksom og kjærlig detalj, og hennes beskrivelse i G lassklokken er akkurat den samme historien. (...) V i snakket død, og dette var livet for oss, det fortsatte på tross av oss.

(Sexton 1970, min oversettelse)

Som svar på de evige spørsmål om hvorfor hun ville ta livet av seg, skrev Sexton diktet "W anting to Die", der hun prøver å forklare hvorfor slike som hun selv og Sylvia Plath var så opptatt av døden og måter å begå selvmord på - til tross for at de i og for seg ikke hadde noe i mot livet:

But suicides have a special language./ Like carpenters they want to know which tools. / They never ask why build.

Død for egen hånd fremstilles som en slags avhengighet.

\section{Karrierebyggende funksjon}

I oppveksten hadde Silvia Plath fått de beste karakterer på skolen og vunnet det som fantes av priser og utmerkelser. Drømmen var tidlig å bli en stor og berømt forfatter. Sitt første dikt fikk hun publisert åtte og et halvt år gammel. Etter at hun ble voksen, gikk det imidlertid tyngre å få innfridd alle forventningene om suksess.
Den eneste lyrikksamlingen som kom ut mens Sylvia Plath levde, T he C olossus (1960), fikk en velvillig mottakelse, men heller ikke mer. Det samme skjedde da The B ell Jar (1963; norsk overs., G lassklokken, 1974) forelå kort før hun døde, en selvbiografisk roman om en ung kvinnes psykiske kollaps, elektrosjokk, selvmordsforsøk og behandling. Berømt og tiljublet ble Sylvia Plath først etter sin død. H ennes ry hviler særlig på A riel (1965), den trykkeklare samlingen hun etterl ot sammen med to små barn.

$\mathrm{H}$ vis ikke Sylvia Plath hadde tatt livet av seg, tror jeg ikke hun i ettertid ville blitt så dyrket og omskrevet som tilfellet er. Interessen omfatter dikterens person vel så mye som verket. Flere årsaker spiller inn, blant annet en allmenn fascinasjon i vår kultur for "de unge døde": begavede kunstnere som tilsynelatende drivesi døden av vanskelige omsten digheter og således bekrefter en utbredt oppfatning av kunstnerenslodd som misforstått og forfulgt geni.

Den selvbiografiske siden ved Plaths forfatterskap bestyrket denne oppfatningen.
$M$ ens T he B ell Jar tok utgangspunkt i et selvmordsforsøk forfatteren så vidt overlevde ni og et halvt år før hun døde, syntes en rekke av A riel-diktene å varsle den endelige døden og tale til publikum fra graven. Selvmordet ga tekstene en både tragisk og pirrende tilleggsdimensjon.

A ndre ble lest som oppgjør med personer som angivelig hadde gjort dikteren ille, først og fremst forel drene og ektemannen, lyrikeren Ted $\mathrm{H}$ ughes. $\mathrm{H}$ an hadde få måneder før forlatt henne og barna "for en annen". Diktenes kvalitet gjorde dessuten at Sylvia Plath kunne erklæres til geni. M en tidspunktet hun døde på, er likevel avgjørende. Ryet hennes vokste parallelt med kvinnebevegelsen, der hun ble adoptert som geni og martyr.

A nne Sexton forsto umiddelbart hvilken betydning selvmordet kunne ha for karrieren og skal til sin psykiater ha uttalt: "den døden var min". H un begynte å planlegge sin posthume berømmelse og drømte om en spektakulær finale, et godt publisert sel vmord og en trykkeklar bok som for all fremtid ville sikre ettermælet hennes.

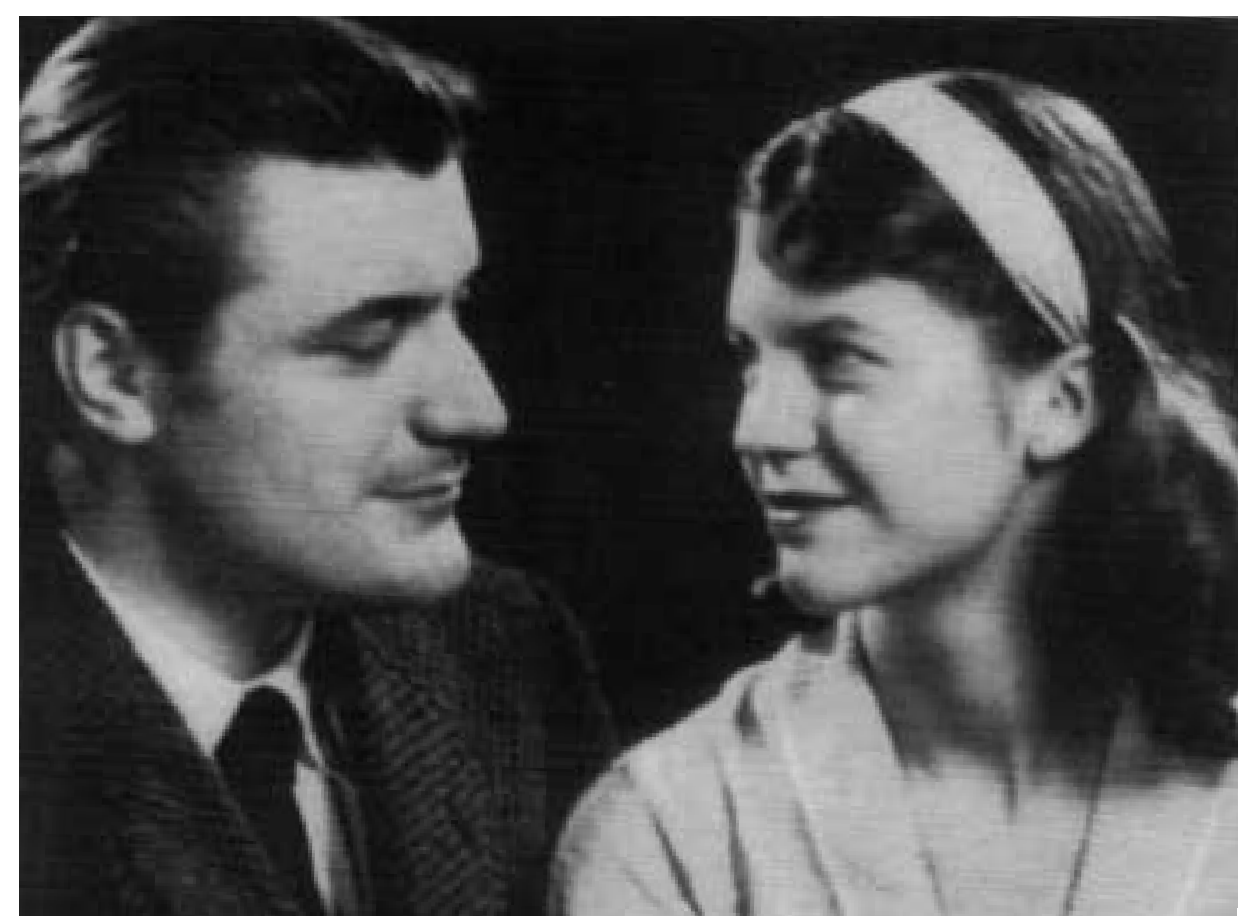

Sylvia med ektemannen, Ted H ughes (1956) 


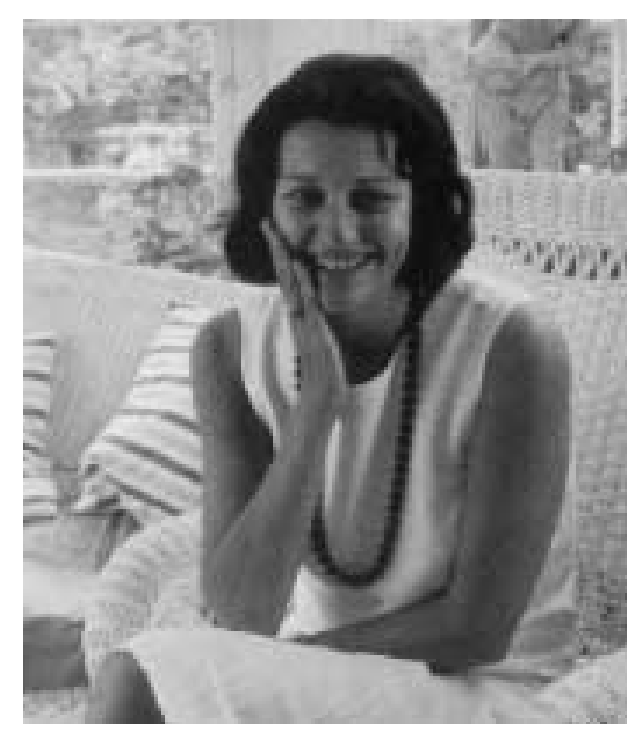

A nne Sexton

Sylvia Plath hadde nærmest stjålet opplegget og dermed snudd opp ned på rangeringen dem imellom. Da Plath døde, var Sexton mest bepriset og anerkjent. $M$ en i og med utgivelsen av A riel endret styrkeforholdet seg, og popularitetskurvene deres pekte i motsatt retning.

Da A nne Sexton tok livet av seg i 1974, var selvmord gammelt nytt. Det virket ikke karrierefremmende for hennes del og ble neppe gjennomført av den grunn heller. H un hadde alkohol- og pilleproblemer, kjente seg ensom, deprimert og mislykket. Skrivingen gikk dårlig. Etter utallige sel mordsforsøk "lyktes" hun.

Sylvia Plath og A nne Sexton var i sin generasjon av diktere langt fra alene hverken om å ha psykiske problemer eller å ta livet av seg. N oe i tiden synes å ha befordret selvdestruksjon og psykisk destabilisering blant kunstnere. Sammenligner man med den engelske Bloomsburykretsen noen tiår tidligere, var Virginia W oolf et unntak. H un begikk selvmord i 1941. I Woolfs miljø ser det ut som om utprøvingen av den seksuelle identitet nærmest var et imperativ. Påfallende mange var bifile og homofile.

\section{Bakgrunn}

I diktet "Lady Lazarus" omtaler Sylvia Plath det å dø som en kunst jeg-personen mestrer usedvanlig godt og noe hun prøver på hvert tiende år: "I guess you could say I've a call." D ersom dette refererer til selvopplevde hendelser, har dikteren poetisert og tilpasset og dessuten diktet opp en fatal ulykke fra da hun var ti år. Imidlertid døde faren, en høyt respektert insektforsker, da hun var åtte. H an fikk diabetes, men trodde det var kreft, tok sykdommen som et tegn på svakhet og oppsøkte ikke lege. En skadet tå endte med amputasjon. Komplikasjoner oppsto, og 0 tto Plath døde i 1940. Sannsynligvis kunne han vært reddet.

$H$ verken Sylvia Plath eller en yngre bror var med i begravelsen. M oren ville skåne dem og holdt tårene sine for seg selv. M ed det man nå vet om sorgreaksjoner og behov for å bearbeide traumatiske opplevelser, kan vi fastslå at dette ikke var særlig klokt, og datteren holdt det senere mot moren. M en A urelia Plath handlet knapt av vond vilje. A mbivalente følel ser til begge foreldrene preger mange av Sylvia Plaths tekster. H un bruker en tradisjonell freudiansk forklaringsmodell på relasjonene dem imellom. Behandlingen hos en psykoanalytisk orientert terapeut kan ha bidradd til dét.

A urelia Plath har blitt tillagt mye ansvar for Sylvia Plaths psykiske problemer både av datteren selv og kommentatorer. Forholdet deres har blitt beskrevet som altfor tett og kvelende. Den sveitsiske psykoanalytikeren $\mathrm{A}$ lice M iller har på et meget spinkelt grunnlag og ut fra en heller enkel litteraturforståelse forklart selvmordet med at datteren ikke klarte å skrive aggressive og ulykkelige brev til moren. $M$ en det kan ikke være riktig. I brevsamlingen som A urelia Plath redigerte, er det mange eksempler på fortvilte og depressive epistler som både gir et godt innblikk i Sylvia Plaths hurtig skiftende sinnsstemninger og viser at omgivel sene kjente godt til dem.

Sylvia Plath ventet konstant støtte og oppbakking av slekt og venner, samtidig som hun syntes å bebreide hjel perne sine for dette, f.eks. at moren "ofret" seg så mye for henne som hun faktisk forlangte. $H$ un fremstår som svært ambisiøs og pliktoppfyllende, med et desperat ønske om å lykkes og høre til blant dem som betydde noe. Verdiene Sylvia Plath internaliserte virker typisk amerikanske og suksessorienterte. M en det lå mye slit bak resultatene hun oppnådde. A rbeidet gikk på helsen løs. H un var på den ene siden sjarmerende, bredt begavet og ressurssterk, på den andre siden merkelig dårlig til à mestre livets al minnelige fortredeligheter, ble lett sjalu og hadde en tendens til å føle seg motarbei det og forfulgt.

Et labilt sinn og en uforsonlig holdning til seg selv, familien og omverdenen åpenbarte seg tidlig. "Det er som om livet mitt på magisk vis styres av to motsatte elektriske strømmer, en frydefull positiv og en desperat negativ - den som løper $\mathrm{i}$ øyeblikket, dominerer livet mitt, oversvømmer det," skrev hun i dagboken sin. 0 verspente forventninger, intens opprømthet og vel dig arbeidsinnsats ble ful gt av skuffelser, selvbebreidelser, bekymringer over ikke å strekke til, fysisk og psykisk utmattel se, skriveblokkering, depresjon og tungsinn.

\section{Forsøk og gjennomføring}

Dette nokså standard reaksjonsmønsteret for Sylvia Plath utspilte seg også sommeren 1953. Etter et opphold i $\mathrm{N}$ ew York som hospitant i et stort ungdomsblad gikk hun inn i en alvorlig depresjon og gjennomlevde antagel ig en identitetskrise. Elektrosjokk ble forordnet poliklinisk. H un reagerte på hver ladning som en henrettelse, tok en overdose sovemedisin og la seg til å sove i kjellerens uutgravde del. En storstilet leteaksjon ble iverksatt. Etter tre dager hørte familien Iyder fra kjelleren. $H$ un hadde tatt for mange tabletter og kastet opp. Behandlingen på en psykiatrisk klinikk gjorde at hun tilsynelatende ble restituert. $\mathrm{H}$ un vendte så tilbake til studiene og fortsatte jakten på troféer av forskjellige slag.

Den som i ettertid prøver å finne ut hvorfor Sylvia Plath flere år senere skrudde på gassen, og det med de to barna til stede i leiligheten, kan krysse av for flere risikofaktorer. Farens tidlige og dramatiske død hører til disse, likeså tidligere selvmordsforsøk.

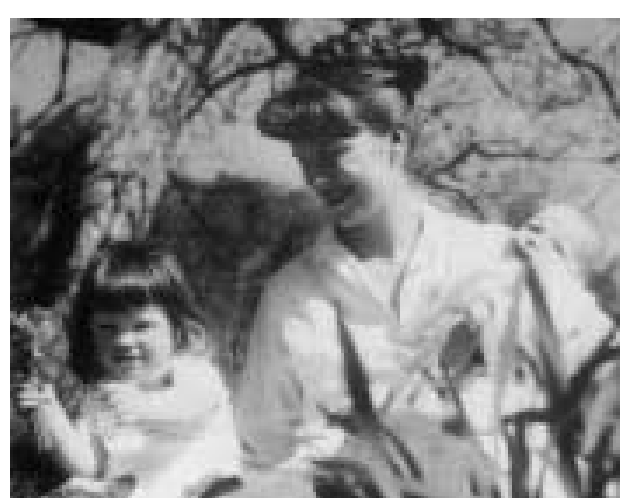

Sylvia Plath med barna, Frida og N icholaus (1962) 


\section{U tdrag fra Lady Lazarus}

D ette er tridje gongen.

For eit mas

å slå i hel kvart tiår.

For ein floke.

D en peanot-tyggjande mengdi

skubbar seg inn for å sjå

kor dei klær av meg på hand og fot -

stor stripe-tease.

H errar, damor,

dette er mine hender,

mine kne.

Eg kan vera skinn og bein,

likevel er eg same kvinna.

Fyrste gongen det hende var eg ti.

Det var ei ulukke.

A ndre gongen meinte eg

å tøygja det ut og ikkje koma

att i det heile.

Eg vogga attlati

Som ei skjel i sjøen.

dei laut lokka og lokka

og plukka makkane av meg som

seige perlor.

$\AA$ døy

er ein kunst, som alt anna.

Eg gjer det uvanleg godt.

Eg gjer det so det kjennest som eit helvete.

Eg gjer det so det kjennest røynleg. Eg trur eg kan segja eg har eit kall.
U ten at diagnosen ble stilt led Sylvia Plath sannsynligvisav en arvelig depressiv lidelse av den bipolare typen, som hun ikke fikk adekvat behandling for. Da ekteskapet raknet, følte hun seg ensom og sviktet av mannen, og praktiske vansker tårnet seg opp.

M en Sylvia Plath hadde også mye å leve for, som de to barna og arbeidet sitt. Til tross for at mange av diktene hun skrev høsten 1962 kom i retur når hun prøvde å få dem publisert, var hun i hvert fall periodevis overbevist om deres kvalitet. Diktene var etterlatt ordnet og systematisert, klare for utgivelse. Både hun og Ted $\mathrm{H}$ ughes håpet dessuten på en gjenforening. $M$ en å leve sammen i fordragelighet med Plaths tekster i fritt omløp ville ha vært vanskelig for alle parter.

Det kan se ut som om hun skrev seg både tom og opp $\mathrm{i}$ et hjørne. A ggressive følel ser overfor ektemannen og foreldrene kom ut i diktene. Skrivingen ga henne for en periode tilfredsstillelse på flere plan og virket kreativt forløsende. $M$ en hun ble ikke mentalt befridd og forsonet. I stedet tok hun livet av seg. Kan hende strakk ikke gamle forklaringsmodeller lenger til. H un foretrakk å se på seg selv som en veltilpasset person med stor

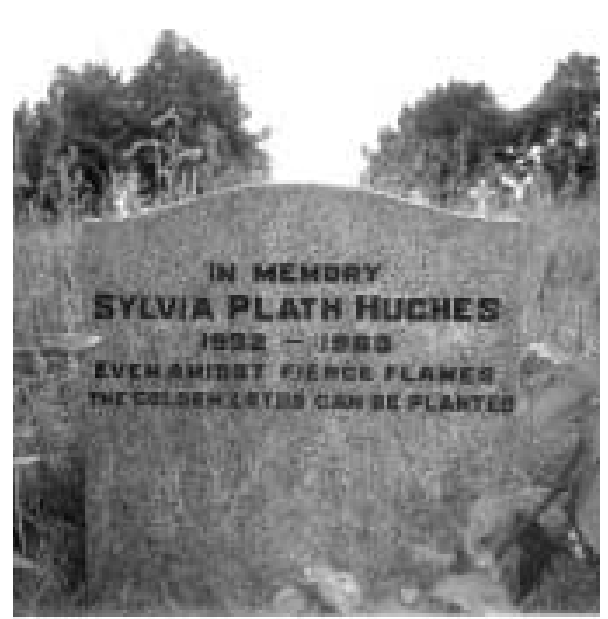

Sylvia Plath er begravet i H eptonstall i Yorkshire. $D$ it valfarter det pilgrimmer av ymse slag. Fire ganger har støtten blitt vandalisert og de profilerte bokstavene i hennes lovformelige etternavn - $\mathrm{H}$ ughes - blitt hakket av. Inskripsjonen er fra det gammelindiske lærediktet B hagavadgita: "E ven amidst fierce flames the golden lotus can be planted." kjærlighetsevne og la helst skylden for problemene sine på andre. Kanskje kom hun frem til en annen erkjennelse?

De aller siste diktene gjenlyder hverken av oppgjør med mytiske fars- og morsskikkelser eller en brutal mannsfigur. Det er livets meningsløshet som tematiseres og døden som den endelige forløser.

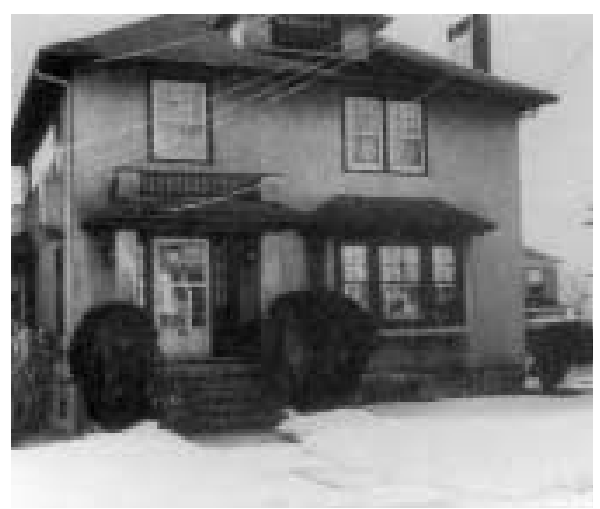

Sylvia Plaths barndomshjem i W inthrop. H er bodde hun til hun var ti år.

\section{Litteratur}

Egel and M . Sylvia Plath. O slo: G yldendal, 1997

M iddlebrook, D.W. A nne Sexton: A Biography. London: Virago, 1991

Miller A . For Your $\mathbf{O}$ wn G ood: T he R oots of Violence in C hild-rearing. London: V irago, 1987

Plath S. Collected Poems. London: Faber and Faber, 1981 (På norsk fins to samlinger med utvalgte dikt, begge fra 1986.)

Plath S. Letters H ome. London: Faber and Faber, 1978

Plath S. T he Journals of Sylvia Plath. N ew York: Ballantine Books, 1987

Sexton A. T he B arfly 0 ught to Sing. I: N ewman $C$, red. The art of Sylvia Plath. London: Faber and Faber, 1970

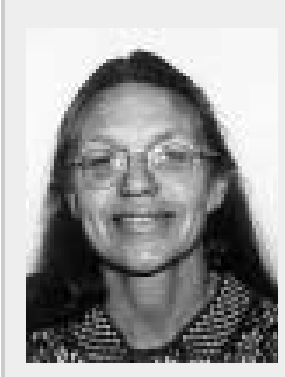

M arianne Egeland er magister i litteraturvitenskap. H un har bl.a. utgitt $L$ andet uten morgendag, Tidsopplevelse og tidspresentasjon i meksikanske romaner etter 1940 (1985), M ed kunnskap skal landet bygges. U niversitetsfor-

laget 1950-1990 (1996), Sylvia Plath (1997), $\mathrm{H}$ vem bestemmer over livet? Biografien som historisk og litterær genre (2000). 